\title{
The White (male) Effect and Risk Perception: Can Equality Make a Difference?
}

\author{
Anna Olofsson and Saman Rashid \\ Risk and Crisis Research Center, Mid Sweden University
}

Article published in Risk Analysis see http://onlinelibrary.wiley.com/doi/10.1111/j.15396924.2010.01566.x/abstract

\begin{abstract}
Previous research has shown that white males have a relatively low perception of risks, known as the 'white male effect' (WME). Many of the explanations of this effect refer to the privileged position of this particular demographic group in society, adducing white males' socio-economic resources, sense of control, worldviews etc. It can thus be argued that inequality leads women and ethnic minorities to have higher risk perception than men and the ethnic majority. Therefore the aim of this study is to investigate the WME in a gender-equal country, Sweden, to see if the pattern is similar to previous studies from the comparably less gender-equal US. The empirical analyses are based on a national survey $(n=1472)$ on the perception of risk conducted in Sweden in the winter of 2005. The results show that in Sweden there is no significant difference between men and women in risk perception, while people with foreign backgrounds perceive risks higher than native people. The chief finding is that there is no WME in Sweden, which it is concluded results from the relative equality between the sexes in the country. On the other hand, ethnicity serves a marker of inequality and discrimination in Sweden. Consequently, ethnicity, in terms of foreign background, mediates inequality, resulting in high risk perception. Equality therefore seems to be a fruitful concept with which to examine differences in risk perception between groups in society, and we propose that the 'societal inequality effect' is a more proper description than the 'white male effect'.
\end{abstract}

KEY WORDS: the white male effect, risk perception, gender and ethnicity, equality 
How to cite: Olofsson, A. and Rashid, S. (2011), The White (Male) Effect and Risk Perception: Can Equality Make a Difference? Risk Analysis, 31: 1016-1032. doi: 10.1111/j.1539-6924.2010.01566.x

Address correspondence to Anna Olofsson, Risk and Crisis Research Center, Mid Sweden University, 83125 Östersund, Sweden, ++4663 165567, anna.olofsson@miun.se 


\section{INTRODUCTION}

The phenomenon known as the white male effect (WME) stipulates that white males differ in their perceptions of risk compared to women and ethnic minorities; white males tend to judge risk lower, particularly compared to women from ethnic minorities. ${ }^{(1-5)}$ A number of explanations have been proposed, among which inequality and differences in world-view are recurring themes. ${ }^{(2-3,6-7)}$ The WME hypothesis was first formulated and empirically tested in the US, and to date the vast majority of investigations are of American origin. Although testing the impact of gender and ethnicity on risk perception has been quite common in risk perception research in general, ${ }^{(8-12)}$ there is a lack of information on the general applicability of the specific WME hypothesis in other socio-cultural contexts than the US. Considering the focus on equality and values in previous studies, an investigation of the WME in a country that differs from the US in terms of equality policy and value systems will contribute new knowledge and further develop the hypothesis. The role of culturally attached world-views as well as differences in societal stratification - the power balance between the sexes and ethnic groups - can thus shed light on the mechanisms that influence the existence of the WME.

The general aim of this study is to investigate whether equality at the societal level influences individual risk perception. This is done by testing for the WME in Sweden, a country that has a different welfare system, demographic structure, political ideology, and general beliefs than the US, but at the same time is similar enough to make comparisons meaningful. ${ }^{(11,13-14)}$ More specifically, the question posed in this article is whether in Sweden men and women, native people, and people with foreign backgrounds ${ }^{i}$ differ in their perception of risk as they have been proven to do in studies from the US? Furthermore, worldviews and vulnerability are used to further analyze the underlying causes of the WME. Consequently, the study contributes to the literature by exploring the WME in a new sociocultural context, accounting for the effect of previously used explanatory factors. However, this study does not measure equality comparatively at the national level, but rather compares analysis on the individual level with previous results in the US. 


\subsection{The white male effect - earlier findings}

At the beginning of the 1990 s, Flynn et al. ${ }^{(2)}$ showed that a subset of white men judge risks to be smaller compared to women and people from ethnic minorities. This group of men has a high education, high incomes, and conservative political views. Further, they are individualists, anti-egalitarian, and trust official bodies. These results have been further investigated in a number of studies in the US. ${ }^{(1,5,7,15)}$ To date, a large number of studies have confirmed differences between men and women, and between different ethnic groups, concerning different risk areas, not least environmental risks. ${ }^{(9,16-26)}$ However, as already noted, the WME hypothesis has mainly been studied in the US. In Sweden, the hypothesis has not been tested explicitly, although separate studies of gender and foreign background indicate that foreign background is correlated with high risk perception, ${ }^{(27-31)}$ and that Swedish women tend to judge risk higher than men do (for an overview, see Enander ${ }^{(27)}$ ). However, there are inconsistencies with regard to the effect of gender. ${ }^{(10)}$

Different factors have been used to explain the WME, from socio-economic characteristics to worldviews and vulnerability. Finucane et al. ${ }^{(1)}$ show that socioeconomic factors are important in explaining the effect: the authors argue that women and ethnic minorities in the US have lower education and levels of income than white men, which is assumed to compound the lower levels of perceived personal control and influence on public issues, so that they rate risks higher than men. ${ }^{(1)}$ According to Hakes and Viscusi, ${ }^{(32)}$ women and ethnic minorities, because of comparatively less science education, also tend to overestimate the probability of death due to various kinds of accidents, while men and people with high education make estimates that are closer to the actual statistics, leaving white men less sensitive to risk. This finding is interpreted as a result of men being more oriented towards science and technology than are women and ethnic minorities. However, several studies of risk perception and gender show that the difference between men and women persists even after controls for education and scientific literacy. ${ }^{(33-35)}$ Nonetheless, men and women, as well as different ethnic groups, seem to be affected by education differently; women tend to be more influenced by education than men are. ${ }^{(32)}$

As already mentioned, the most common explanation for this is differences in worldviews or general beliefs. ${ }^{(2)}$ Cultural theory, based on Mary Douglas' 'grid-group' typology of cultural bias, is frequently used as theoretical model. ${ }^{(36)}$ Concern about risks is based in socio-cultural factors, individuals are thus embedded in a social structure that shapes 
their worldviews as well as their understanding of risk. ${ }^{(37)}$ These world-views are collectively shared constructs, or cultural biases, which determine the individual's perceptions. ${ }^{(38-39)}$ The grid dimension roughly represents 'social control', while the group dimension represents 'social commitment'. Together they construct a two-by-two typology of ideal type cultural values. The typology is the source of several different empirical measurements of cultural bias, of which Dake constructed one of the first. ${ }^{(38)}$ The most common typology is: egalitarianism, hierarchy, fatalism, and individualism. ${ }^{(40-43)}$ Using value indicators based on cultural theory, Finucane et al. show that world-views differ between the groups: ${ }^{(1)}$ white males have individualistic and hierarchical world-views, while women and ethnic minorities are more inclined to egalitarian world-views. This is confirmed by Palmer, who shows that Taiwanese men in the US, with the same kind of individualized and hierarchical world-views as white males, express a low risk perception similar to that of white men. ${ }^{(5)}$ However, she merely concludes that there are differences between ethnical groups and between men and women, not controlling for other factors such as education and age, or investigating the interrelations between the different factors.

Using another theory of values, the value belief norm theory (VBN), ${ }^{(44-46)}$ Kalof et al. show in a similar study that white males have dissimilar values and beliefs compared to women and non-white groups in the US. ${ }^{(4)}$ Although Kalof et al. convincingly show this difference, they do not empirically test the interrelationship between WME and values. ${ }^{(4)}$ Kahan et al., on the other hand, not only stipulate that cultural world-views correlate with gender and origin, they show it empirically. ${ }^{(3)}$ They investigate both confounding factors and the interrelationship between worldviews, ethnicity, gender, and risk perception. Their results show that worldviews, based on cultural theory, moderate the impact of gender and ethnicity on risk perception. They argue that the WME is a consequence of the individual protection of cultural identity, and thus women and men, as well as different ethnic groups, will form different risk perception in a manner that prevents them from obstructing the activities on which their identities depends. The same thing accounts for cultural bias: people who identify with individualistic worldviews, for example, will feel more threatened by risks related to limitations of individual freedom. ${ }^{(37)}$ Kahan et al. find support for the theory in their empirical investigation of risk related to abortion, guns and the environment. ${ }^{(3)}$ For example, people with individualistic worldviews are less negative toward guns. This confirms the impact of values, or worldviews, in understanding the WME. 
Except for the assumption that values influence people's risk perception, vulnerability, in terms of exposure to risk and inequality, has also been investigated as a possible explanation of the WME. Previous research indicates that perceived exposure to a certain risk increases the fear of it. ${ }^{(47)}$ The 'environmental (in)justice thesis', ii states that minority populations are subject to health risks, and indeed other risks stemming from modern society, to a greater degree than the majority population, due to segregation and differences in economic resources. ${ }^{(7)}$ It is also known that people living in polluted residential areas generally judge risks to be higher than comparable people living in non-polluted areas. However, when this difference is controlled for, for example by studying differences between the sexes and ethnic groups in a polluted area, white males still have the lowest risk perception and women from ethnic minorities the highest. ${ }^{(48)}$ However, Satterfield, Mertz, and Slovic show that men with experiences of exposure to discrimination, or vulnerability, also have higher perceptions of health risks (the risk in question). ${ }^{(7)}$ Hence, experiences of discrimination as well as economic and physical disadvantage might explain why women and ethnic minorities are more sensitive to different kinds of risks. Vulnerability can then be defined in terms of individually perceived fragility, economical insecurity, and/or ill health. ${ }^{(49-52)}$ So far previous studies have used vulnerability as a theoretical rather than an empirical explanation, or have only empirically analyzed a single kind of risk, for example health risks, not following the approach adopted by Flynn et al. of including an entire range of risks. ${ }^{(2)}$

Before the data and methods used in this article are presented, the socio-cultural contexts of the US and Sweden are described and the definition of the WME is presented.

\subsection{Societal equality in the US and Sweden}

Needless to say, there are both numerous differences and similarities between the US and Sweden. However, there are some differences that are especially relevant in explaining WME, primarily related to the welfare system and political ideology. However, first a few words about the Swedish population and how ethnicity is defined in Sweden compared to the US.

Previous research on the WME has defined ethnicity in terms of the different ethnic groups in the US, for example African-American, Hispanic, and Caucasian. In the US it is not unusual to categorize the population according to ethnicity and even race: in Sweden, as in the 
rest of Europe, race is rarely used to describe or categorize people for obvious historical reasons. Ethnicity is not a commonly used term either, at least not to describe majority groups like native Swedes. Instead, ethnicity is something generally ascribed to people with foreign backgrounds, particularly non-white people, by the majority population. ${ }^{(67-68)}$ Furthermore, ethnicity is not used in public records in Sweden - 'Swedish' is not defined as an ethnicity. Unlike the US, with its history of immigration and a diverse population, Sweden has moved from an emigration country in the nineteenth century to being a recipient country today: by the end of the nineteenth century Sweden had lost about one million inhabitants, a figure that broadly corresponds with the number of people who have come to Sweden over the last fifty years. Today at least 16 percent of the Swedish population has a foreign background. ${ }^{(59)}$ This means that unlike the US, Sweden has traditionally had a rather homogeneous population that only recently become more diverse. Some researchers have even called Swedish society a monoculture. ${ }^{(75)}$ Sweden should be considered as a diverse society in the making, where ethnicity is closely related to the difference between being native or being foreign, rather than to race or subgroups of the native population.

We would argue that in Sweden native people are comparable to the 'white' ethnic group in the US, and hence what in the US is a white male effect should by rights be a native male effect in Sweden. Although originating in, say, Turkey, is not the same as being Hispanic or African-American in the US, in Sweden it is perceived as an ethnicity. According to other studies of ethnicity in Sweden, Swedes operationalize white males as men with a native background (born in Sweden of two Swedish-born parents). Non-white equals foreign background (born in a country in Eastern Europe, Asia, Africa, or South America, or born in Sweden but with at least one parent born in these regions). More details are given in the Methods section; for now, let us turn to differences in welfare models and policy between the two countries.

On a general level, the Swedish welfare model is designed to create equality across different social classes, gender, and so on through state intervention, while the American liberal welfare system depends on the free market and individual autonomy to create wellbeing and prosperity for the population. ${ }^{(13)}$ Even though Sweden has become more oriented towards liberal policy and individual responsibility over the last decades, the difference compared to the US is still considerable. ${ }^{(72)}$ Just as overall welfare policy is reflected in systems of social security and labor market regulation, it is also echoed in general beliefs and 
value systems. Numerous studies also confirm that Sweden and the US differ in general beliefs on an aggregated level. ${ }^{(14,53-55)}$

Together with the other Nordic countries, Sweden is often regarded as more egalitarian and less gendered than other countries. ${ }^{(56,71)}$ A study of attitudes towards gender equality that compared 61 countries around the world shows that Sweden and Finland ranked as the most egalitarian. ${ }^{(70)}$ Of course, gender equality is also an important issue in the US, yet income distribution and other aggregated measurements of equality are different compared to Sweden. In a measurement of the so-called gender gap by the World Economic Forum in 2005, Sweden was ranked highest out of 58 countries. ${ }^{(57)}$ The US, on the other hand, had an overall rank of 17, and came as low as 46 and 42 when it came to 'economic opportunity' and 'health and well-being' (where Sweden ranked 12 and 1 respectively). The study also documented considerable differences in gender policy profiles between the two countries. ${ }^{57}$, 72)

Turing to diversity and ethnic heterogeneity the picture is different. The US has a history of diversity, with a continuous flow of immigration, in the past not all of it voluntary. Thus, race and ethnicity are concepts that have long been part of policy, regulation, public debate, and everyday life. ${ }^{(58)}$ Sweden, on the other hand, has only recently become diverse in terms of ethnicity, and as a consequence has largely been spared open racial conflicts, even though discrimination and latent racism exist, for example on the labor market. ${ }^{(60-64)}$ The US, together with Canada, Australia, and South Africa, has the most comprehensive civil legislation and compulsory affirmative action against discrimination. ${ }^{(65)}$ Many European countries, including Sweden, instead have chosen to emphasize legislation in the prevention of hate speech and the organization of fascist and racist groups. The conclusion is that both the US and Sweden have problems with ethnic discrimination and racism, but the countries' history and current situation is quite different when it comes to legislation, economic opportunities, and welfare.

\subsection{Testing the white male effect in Sweden: expected outcomes}

The design of the present study follows previous research on WME. Perceptions of seventeen different risks are studied among men and women, native people as well as people with foreign backgrounds. Explanatory variables included in the analyses are also similar to previous research - education, age, marital status, and worldviews. The latter, based on 
cultural theory, measures individualistic, hierarchical, egalitarian, and fatalistic worldviews. We have not included attitudes to other constructs such as technology or the environment, although research has indicated that such attitudes may play a significant role in risk perception, particularly among white males. ${ }^{(1,2,76)}$ The reason is that there is a risk that respondents do not differentiate between, for example, environmental risk, as in the "new ecological paradigm' scale, and specific risk perception, so that the same thing is measured twice. ${ }^{(10)}$ Instead we added measurements of vulnerability to the analyses, in the form of experience of risks and social inclusion. All the variables are described in detail in the following section, Methods.

Considering all the differences in gender and ethnic policy described above, it is a challenge to compare Sweden with the US in terms of the WME hypothesis. The comparatively greater gender equality and less experience of racial conflict, combined with a state-based social security system and a different view of ethnicity, means that explanations based on inequality, lack of control, and social exclusion might not be as self-evident as in the US. In fact, if these explanations are indeed the mechanisms behind the WME, one should expect there to be no such effect in Sweden, at least not concerning gender. Ethnicity is different since there are many indications of inequality in Sweden based on place of origin and thus ethnicity. Hence, we expect that gender will not affect perception of risk, but that ethnicity will.

Concerning the remaining independent variables, we expect effects similar to previous studies: lower risk perception among people with high education, older people, individualists, and those with a hierarchical worldviews, little previous experience of risk, and those who feel socially included. ${ }^{(1-7,76)}$ However, we also expect variation in effects depending on the kind of risk rated. ${ }^{(73)}$

\section{METHODS}

The analyses were made with data from a Swedish national survey ('Society and Values') conducted as a postal questionnaire in the winter of 2005. The dataset used in the analyses is composed of two representative samples of the Swedish population aged between 16 and 75. The samples consist of a national random sample $(n=2000$, response rate 59 per cent) and a random sample of people living in three districts in Stockholm, Gothenburg, and Malmö ( $\mathrm{n}=750$, response rate 39 per cent ${ }^{\mathrm{iii}}$ ). This second sample comes from residential areas 
with a relatively large population of people with foreign backgrounds. The aim of the second sample was to increase the number of the latter in the dataset, who otherwise might have been too few to use in statistical analyses, and because of language problems and incorrect addresses, the response rate of the second sample was expected to be low. The total number of respondents is 1472 .

\subsection{Variable presentation and econometric specification}

The survey has a total of 380 questions about risks, risk communication, world-view, social resources, vulnerability, and socio-economic status. The questions are based on previous studies ${ }^{(\text {e.g. } 2,38,43,66)}$ and a preliminary study with five focus group interviews. ${ }^{(31)} \mathrm{A}$ selection of questions about risks, worldviews, and vulnerability have been used.

The present study follows the design of the initial investigations of the WME ${ }^{(1-2)}$ so that a considerable variety of different risks are investigated. It is well known that scholars usually do not observe individual 'underlying' preferences or responses such as risk perception. Instead, such latent variables will be observed only through discrete indicators. As this is the case in the present study, people's underlying perceptions of different risks were observed through seventeen questions about different kinds of risks (see Table I) varying according to five categories of risk (Very big, Big, Moderate, Small, and Very small), which are inherently ordered. It is well documented from earlier studies that people judge risk differently depending on the risk target: risk for others is perceived as larger than risk for the individual personally. ${ }^{(35)}$ In the survey, both kinds of questions were asked, and we have chosen to present how people perceive risks for themselves personally, in order not to exaggerate peoples' risk perception.

To test the WME, gender and ethnicity are included in the specification of the model, although the term 'ethnicity' was not used in the survey for the reasons discussed in section 1.2 above. Instead the participants were asked about their own origin and that of their parents, and people who were born, or have at least one parent born, in Asia, Africa, Eastern Europe, or South America ${ }^{\text {iv }}$ were categorized as having a 'foreign background' (see Table I). To explicitly test the effect of being a man and native, the interaction effect of ethnicity and gender was also included in the analyses.

Of the respondents categorized as having a foreign background, 44 per cent originated in Asia, 41 per cent in East Europe, 8 per cent in Africa, and 7 per cent in South America. 
Merging people with such different backgrounds into one group might be considered problematic: there is always a possibility that the internal consistency in risk perception would be lower in this group compared to the native group because of different experiences and cultures, which would violate certain conditions for performing multiple regressions. In order to control internal consistency, the standard deviations are reported in Table I for four groups: men with native backgrounds, women with native backgrounds, men with foreign backgrounds, and women with foreign backgrounds. ${ }^{\mathrm{V}}$ The figures in Table I show that there are marginal differences in standard deviation between men and women, but that the variation in standard deviation between the seventeen dependent variables is greater among native people than among people with foreign backgrounds. However, there is more variation concerning all variables among people with foreign backgrounds compared to native people. Still, we do not consider the overall difference between the groups to be so large as to be considered a problem in further analysis.

Table I: Presentation of dependent variables and descriptive statistics.

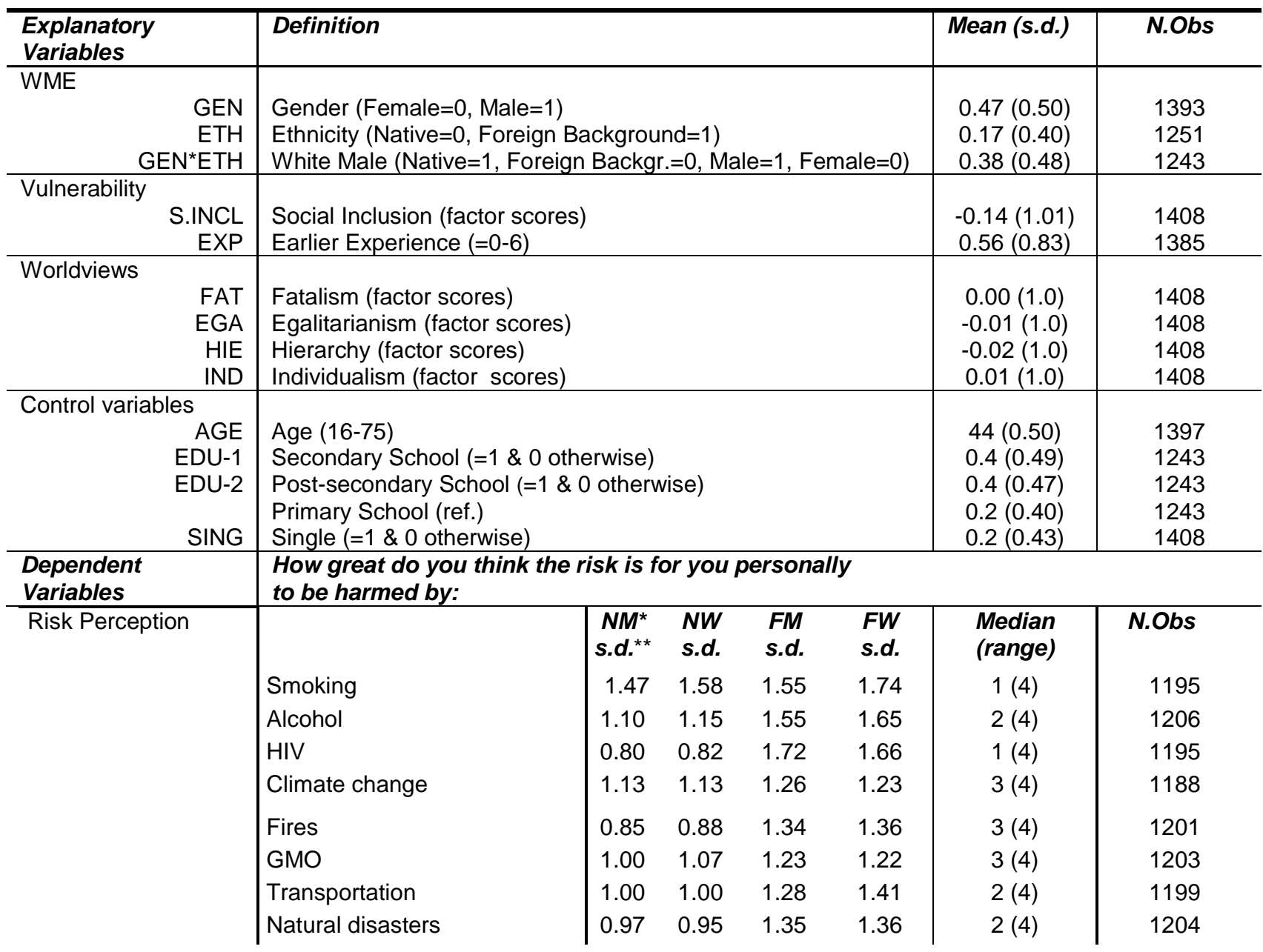




\begin{tabular}{|l|llll|l|l|} 
Violence & 0.96 & 0.99 & 1.29 & 1.42 & $3(4)$ & 1186 \\
BSE & 0.72 & 0.79 & 1.26 & 1.41 & $2(4)$ & 1186 \\
Technological systems & 1.08 & 1.06 & 1.12 & 1.26 & $3(4)$ & 1183 \\
Accidents (leisure time) & 0.85 & 0.89 & 1.08 & 1.19 & $3(4)$ & 1194 \\
Terrorism & 0.92 & 0.91 & 1.46 & 1.54 & $2(4)$ & 1190 \\
Stress & 1.16 & 1.15 & 1.16 & 1.09 & $3(4)$ & 1189 \\
Epidemics & 0.83 & 0.88 & 1.36 & 1.44 & $2(4)$ & 1189 \\
Cancer & 0.90 & 0.92 & 1.26 & 1.29 & $3(4)$ & 1206 \\
Traffic accidents & 0.83 & 0.79 & 1.14 & 1.26 & $3(4)$ & 1206
\end{tabular}

*NM = Native Men, NW = Native Women, FM = Men with Foreign backgrounds, FW = Women with Foreign backgrounds.

**The Standard Deviation figures should be interpreted with care since ordinal scales have been used. The correct measurement is range, however in this case with scale where the scale ranges from 1 through 5 , the range is 4 for all 17 variables, the same as for the whole sample.

Following previous studies of the WME, worldviews, measured using a revised cultural theory index composed of sixteen questions, were used as an explanatory factor. ${ }^{(38,43)}$ The index was analyzed, using principal component analysis, varimax rotation, giving the expected four factors (explained variance 0.435): fatalism, egalitarianism, hierarchy, and individualism. Regression scores for each respondent were used in the statistical analyses. The questionnaire also included questions about social inclusion and exposure - vulnerability, in other words. To measure social inclusion an index was constructed from eight items, for example, Swedish society is open to people like me; If I had the opportunity I would rather live in a different country than Sweden; and A small group decides what is Swedish and what is not (explained variance .326, Cronbach Alpha .698). Here too regression scores were used in the analysis. Another index was created of questions about previous experience of risk. Six kinds of risk were included: (domestic) fire, natural disaster, violence, war/terrorism, traffic accident, serious illness and serious accidents. The six potential experiences were added up to an index ranging from 0 through 6 .

Lastly, questions about age, education, and marital status were included, used in the analysis as control variables, since previous research has shown their significance. ${ }^{(35)}$ In cases where age has an effect, older people, for example, tend to worry more about illnesses and crime, while younger people perceive stress to be a greater risk. ${ }^{(72)}$ The effect of age depends in other words on the kind of risk in question. ${ }^{(47,73)}$ Education is perhaps more interesting, since previous studies of WME show its relevance. ${ }^{(1-2)}$ Studies from the US also indicate that women are more influenced by education than men are. ${ }^{(32)}$ Furthermore, education can also be used as a proxy for income. It is not possible to use both education and income since they are highly correlated, and the reason for using education alone and not income is the problem of discrimination: people with foreign backgrounds are more likely to be subject to income 
discrimination. Education on the other hand, particularly measured in years in school, is a fairly comparative measurement. Furthermore, the measurement of income can become biased in the process of measurement, since respondents might overlook the definition of income in the survey: questions about whether different kinds of social security and income taxes should be included might be missed by the respondent, even though it is specified in the questionnaire (this particular question requires a fair amount of information for the respondent, and hence the chance of misunderstanding increases). Although there probably are differences between population groups such as men and women as well as native people and people with foreign backgrounds, education remains a better measurement than income.

Thus, we denote the individual's underlying responses to different kind of risk perception as $Y_{i j}^{*}$, when $j$ denotes the type of risk to which the individual $i$ responds. As mentioned earlier, we only observe the category to which the individual's responses belong. Thus, we may define individual $i$ 's response to risk type $j$ as $Y_{i j}$, and the equation may be expressed as follows:

$$
\begin{array}{r}
Y_{i j}=\alpha_{j} G E N_{i j}+\beta_{j} E T H_{i j}+\delta_{j} I N C L_{i j}+\lambda_{j} E X P O_{i j}+\eta_{j} F A T_{i j}+\gamma_{j} E G A_{i j}+\rho_{j} H I E_{i j}+ \\
+v_{j} I N D_{i j}+\kappa_{j} A G E_{i j}+\chi_{j} E D U 1_{i j}+\sigma_{j} E D U 2_{i j}+\tau_{j} G E N^{*} E T H_{i j}+\varepsilon_{i j}(1)
\end{array}
$$

where the variables on the right-hand side are assumed to be exogenous explanatory variables, $\alpha$ through $\tau$ are unknown parameters to be estimated, and $\varepsilon_{i j}$ is the error term. Since the observed dependent variables - the individual risk perception - are categorical and ordered inherently, we may assume that $\varepsilon$ is normally distributed across observations, ${ }^{(69)}$ and it is proper to employ an ordered probit model.

\section{RESULTS}

The findings are divided in two sections. The first section is descriptive and follows the approach adopted by Flynn et al. ${ }^{(2)}$ Analyses of perceived risk among men and women, and people with foreign backgrounds and native people, are first presented and then followed by a comparison of risk perception ratings by both gender and origin (i.e. men with foreign backgrounds, women with foreign backgrounds, native men and native women). The second section is analytical. WME is explored with the help of multivariate analyses of the 
explanatory factors of world-view and vulnerability, and the control factors of age, education, and marital status.

\subsection{Descriptive analyses of WME in Sweden}

Figure 1 shows the percentage difference between men and women when male high-risk responses (when a risk as rated as 'Very big') have been deducted from female high-risk responses. ${ }^{(2)}$ In accordance with the WME hypothesis and previous studies in the US, women perceive risk to be higher than men do, as is indicated by the fact that women have higher values for all hazards. The biggest differences are found in the perception of smoking, stress, and genetically modified organisms (GMO). The resulting fourteen differences are relatively minor, and certainly not as large as in the American studies. ${ }^{(1,2)}$

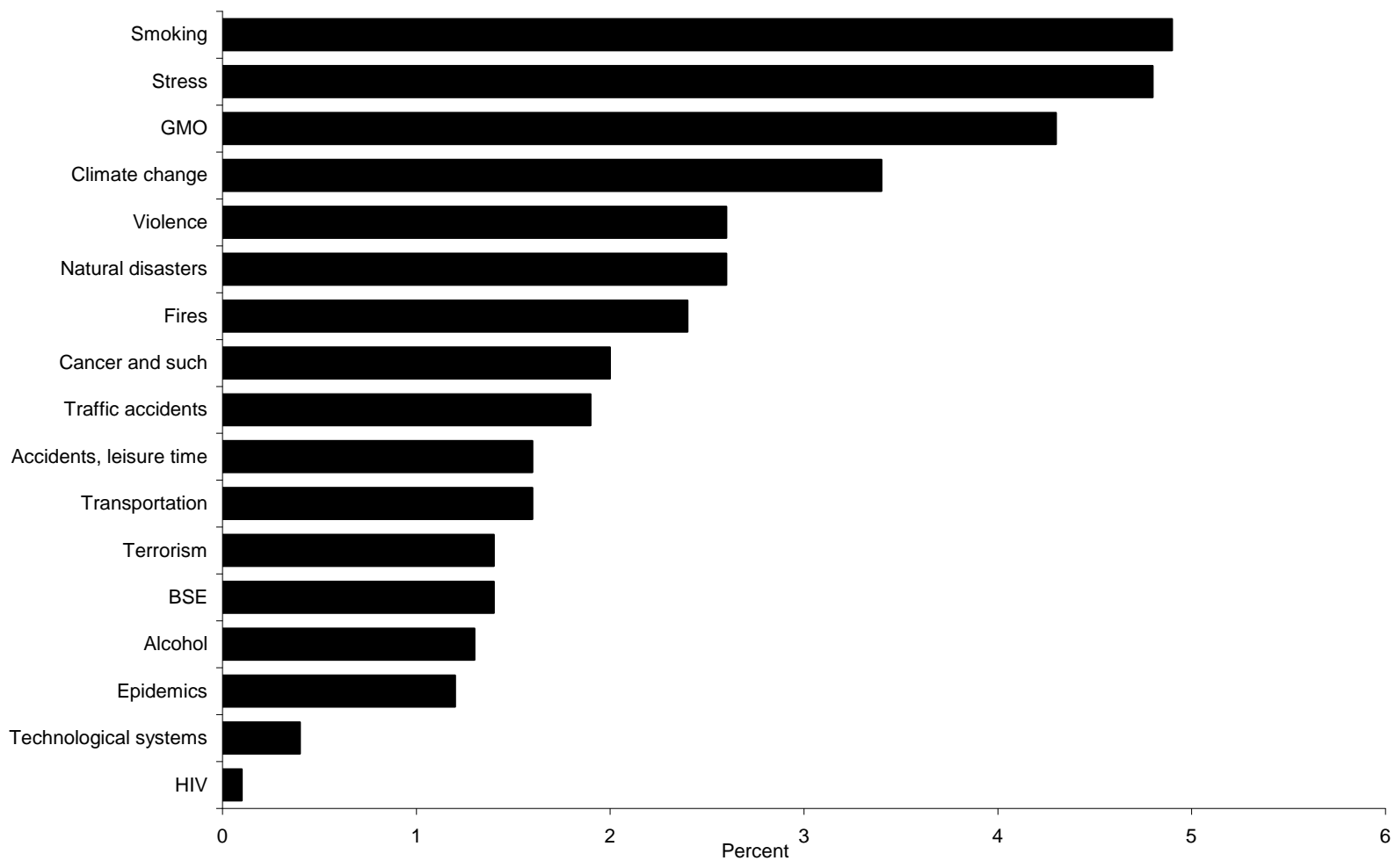

Figure 1. Perceived risk to the Swedish public by gender, difference in per cent. Percentage difference is female high-risk response minus male high-risk response.

Testing gender differences with a simple chi-square test shows that only four differences are significant at the 95 per cent level; climate change, genetically modified organisms, natural disasters, and stress. ${ }^{\text {vi }}$ This confirms that these results differ from previous American studies. 
Similarly, Figure 2 shows the difference in high-risk responses between people with foreign backgrounds and native people. In this case the differences are striking. The biggest differences are found in perceptions of HIV, terrorism, fires, natural disasters, and illness, while there are only a few risks where the differences are minor: climate change, accidents related to leisure activities, and technological systems. In other words, the Swedish findings correspond to earlier US studies of differences between majority and minority groups.

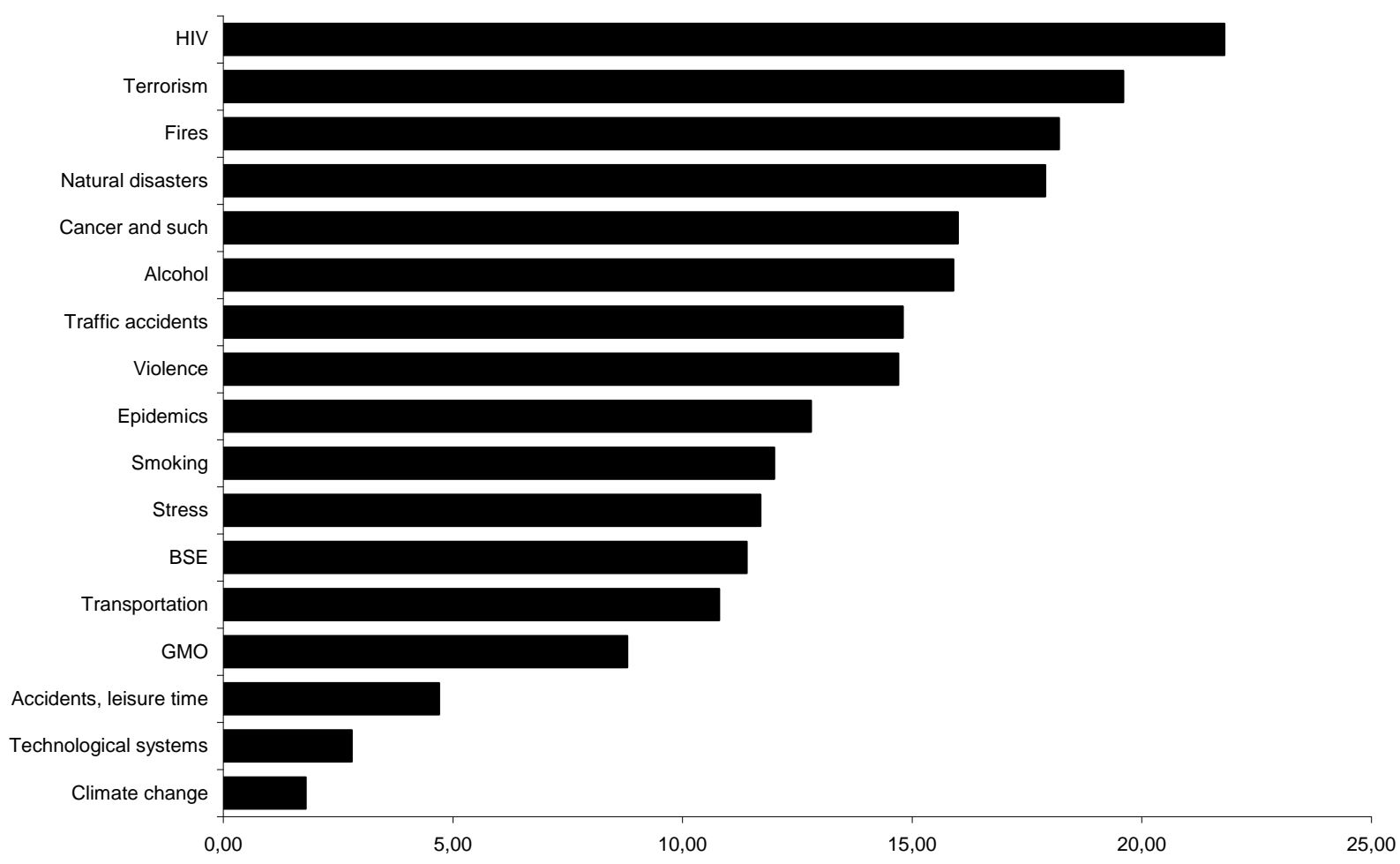

Figure 2. Perceived risk to the Swedish public by origin, difference in per cent. Percentage difference between high-risk responses from people with foreign backgrounds and high-risk responses from native people.

Once again, we tested the differences with the chi-square test, and this time all differences except climate change and technological systems were significant at the 95 per cent level. This confirms that the differences are more stable between ethnic groups than between men and women.

Now let us see how the results compare with previous studies when gender and origin are combined. In Figure 3 the results for native men, native women, men with foreign backgrounds, and women with foreign backgrounds are presented. The figure shows the percentage difference of high-risk responses of the last three groups deducted from native 
men's high-risk responses (white males). Across all seventeen hazards, except HIV and climate change, women with foreign backgrounds give the highest risk perception ratings. HIV is rated highest by men with foreign background, and there is no difference in the perception of climate change between the groups. All differences except for perceptions of climate change and technological systems are significant at the 95 per cent level.

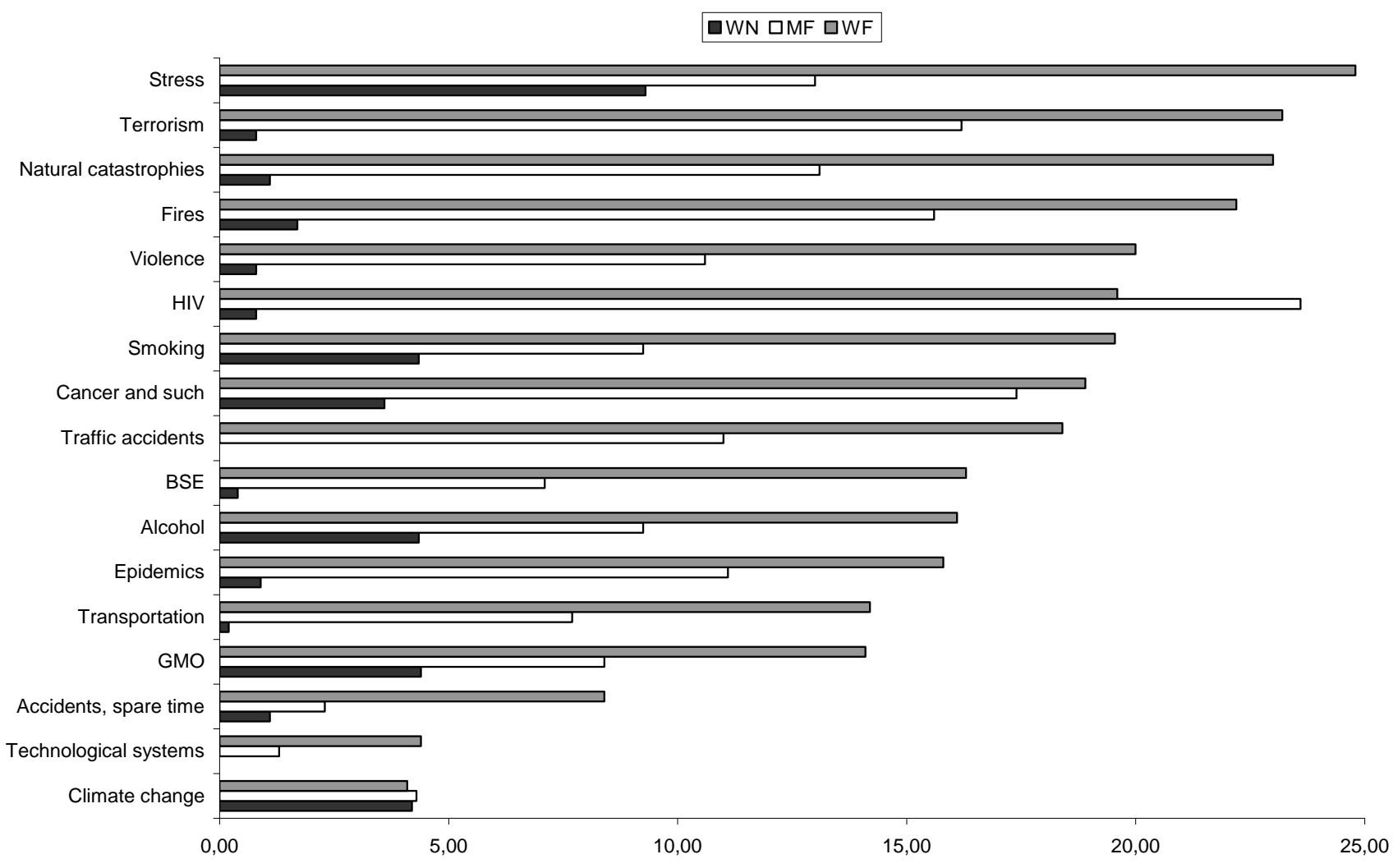

Figure 3. Perceived risk to the Swedish public by origin and gender, difference in per cent. Percentage difference is men and women with foreign backgrounds and native women, high-risk response, minus native men high-risk response.

Compared to previous American studies, origins seem to have a stronger impact than gender, which is also evident in the results from the two earlier figures (Figures 1 and 2). Terrorism, natural disasters, violence, traffic accidents, BSE, epidemics, and transportation are all examples where origins seem to be a stronger factor than gender.

To sum up, the descriptive analyses have indicated that there might be a WME in Sweden, although unlike previous American studies the effect of ethnicity tends to be stronger than gender. To investigate further the relationship between gender, ethnicity, and risk 
perception, when other possible explanations have been controlled for, analytical tests are needed.

\subsection{Analytical analyses of WME in Sweden}

Multiple ordered probit regression analyses were conducted to see if the differences found in the descriptive analyses remain when other factors - age, education, marital status, previous experiences of hazards, social inclusion, and world-view - are included in the analysis. To identify the effect of the different variables, three regression models have been used:

- Model 1 includes gender, ethnicity, and WME, and the control variables (age, education, and marital status).

- Model 2 includes gender, ethnicity, and WME, the control variables, and worldviews.

- Model 3 includes gender, ethnicity, and WME, the control variables, worldviews, and vulnerability (previous experiences and social inclusion).

The three models have been run for all seventeen different risks, and Table II presents a summary of the results (all results are presented in full in Tables A-C in the Appendix), in total of 51 regression analyses.

First of all, the interaction effect of both being a man and a native, WME, does not show any significant relationship with the seventeen different risks, a result in line with the descriptive analysis, but quite unlike previous studies. ${ }^{(1,2)}$ In Model 1 (see Table A in the Appendix), native men have a higher perception of risk than other groups regarding accidents during leisure time, but this relationship becomes much weaker in Models 2 and 3 (see Tables $\mathrm{A}$ and $\mathrm{B}$ in the Appendix). Consequently, the combination of being a native and a man does not make a difference in Sweden. In the further analyses, the focus is instead on the unique effect of gender and ethnicity (see Table II).

Model 1 in Table II shows that gender has a significant relationship with four kinds of risks when ethnicity, age, education, and marital status are controlled for. These are the same four risks as in the descriptive analysis, except GM food is exchanged for accidents during leisure time. The inclusion of worldviews does not change this pattern, as Model 2 demonstrates. However, when vulnerability in terms of previous experiences and social inclusion are included in the analysis, two of the risks, climate change and accidents during 
leisure time, are no longer significant. Thus an important conclusion can be drawn: unlike the US, gender does not play a significant role in people's risk perception in Sweden.

The effect of ethnicity, or place of origin, is significantly related to thirteen of the seventeen different risks after controlling for gender, age, education, and marital status (see Model 1 in Table II). Compared to the descriptive analysis, in which climate change and technological accidents were the only insignificant risks, in Model 1 accidents during leisure time and illnesses such as cancer are also insignificant. The addition of worldviews to the analyses (see Model 2 in Table II) does not have an immense effect. The correlation between ethnicity and perception of alcohol-related risks is no longer significant, but instead ethnicity and perceptions of accidents during leisure time show a weak correlation. In Model 3, traffic accidents are no longer significantly related to ethnicity, but there are still thirteen out of seventeen risks that have a significant correlation with ethnicity. From these results the conclusion can be drawn that ethnicity has a unique and significant effect on risk perception in Sweden.

Table II. Summary of order probit regression models. Model 1 includes gender, ethnicity, and control variables; Model 2 includes gender, ethnicity, control variables, and worldviews, and Model 3 includes gender, ethnicity, control variables, worldviews and vulnerability. (The results of each individual regression are presented in Tables $\mathrm{A}-\mathrm{C}$ in the Appendix.)

\begin{tabular}{|c|c|c|c|c|c|c|c|}
\hline \multirow[b]{2}{*}{$\begin{array}{l}\text { Dependent } \\
\text { Variables }\end{array}$} & \multicolumn{3}{|c|}{ GENDER } & \multicolumn{3}{|c|}{ ETHNICITY } & \multirow[t]{2}{*}{$N-O B S$} \\
\hline & Model 1 & Model 2 & Model 3 & Model 1 & Model 2 & Model 3 & \\
\hline Smoking & -0.08 & -0.08 & -0.04 & $0.67^{* *+}$ & $0.49^{* \star *}$ & $0.37^{\prime * m}$ & 1187 \\
\hline Alcohol & 0.20 & 0.18 & 0.22 & $0.27^{*}$ & 0.16 & 0.13 & 1198 \\
\hline HIV & 0.13 & 0.08 & 0.12 & $0.77^{\star \star \star}$ & $0.64^{\star \star \star}$ & $0.59^{* * *}$ & 1187 \\
\hline Climate change & $-0.30^{*}$ & $-0.29^{*}$ & -0.27 & 0.10 & 0.07 & -0.04 & 1180 \\
\hline Fires & -0.16 & -0.18 & -0.12 & $0.46^{* * *}$ & $0.40^{* \star *}$ & $0.38^{* *}$ & 1192 \\
\hline GMO & -0.24 & -0.22 & -0.19 & $0.40^{\star \star * *}$ & $0.39^{* \star *}$ & $0.31^{* *}$ & 1195 \\
\hline Transportation & -0.13 & -0.11 & -0.06 & $0.51^{\star \star \star}$ & $0.45^{\star \star \star}$ & $0.35^{\star *}$ & 1191 \\
\hline Natural disasters & $-0.42^{* *}$ & $-0.41^{* *}$ & $-0.36^{* *}$ & $0.86^{* * *}$ & $0.80^{* * *}$ & $0.66^{* * *}$ & 1196 \\
\hline Violence & -0.17 & -0.19 & -0.12 & $0.51^{\star * *}$ & $0.54^{* \star \star}$ & $0.41^{\star \star}$ & 1186 \\
\hline BSE & -0.29 & -0.29 & -0.24 & $0.99^{* * *}$ & $0.87^{* \star *}$ & $0.80^{* * *}$ & 1178 \\
\hline Tech. systems & 0.02 & -0.01 & 0.03 & -0.03 & -0.03 & -0.07 & 1181 \\
\hline $\begin{array}{l}\text { Accidents (leisure } \\
\text { time) }\end{array}$ & $-0.34^{*}$ & $-0.36^{*}$ & -0.31 & 0.23 & $0.29^{*}$ & $0.28^{*}$ & 1181 \\
\hline Terrorism & -0.19 & -0.21 & -0.17 & $0.79^{\star \star \star}$ & $0.75^{\star \star \star}$ & $0.66^{* * *}$ & 1183 \\
\hline Stress & $-0.38^{* *}$ & $-0.39^{* *}$ & $-0.35^{* *}$ & $0.47^{* * *}$ & $0.43^{\star \star \star}$ & $0.31^{* *}$ & 1191 \\
\hline Epidemics & -0.17 & -0.18 & -0.14 & $0.67^{\star \star \star}$ & $0.63^{\star \star \star}$ & $0.55^{* * *}$ & 1181 \\
\hline Cancer & -0.07 & -0.08 & -0.01 & 0.21 & 0.17 & 0.08 & 1200 \\
\hline Traffic accidents & -0.05 & -0.07 & -0.01 & $0.31^{* *}$ & $0.31^{*}$ & 0.26 & 1197 \\
\hline
\end{tabular}


Before discussing these results further, we would like to comment on the effect of the control variables and remaining explanatory variables (see Tables $\mathrm{A}-\mathrm{C}$ in the Appendix). Worldviews show less stable correlations to the different risk ratings than vulnerability does. Previous experiences of risks are significantly related to all seventeen risks; the greater the experience the higher the risk perception. These relationships are significant after controlling for gender, ethnicity, WME, age, education, marital status and worldviews. Thus, earlier experience is the most stable predictor of risk perception in this material. Social inclusion, in terms of feelings of belonging in the country and the social context, does not show a similarly strong relationship, but is significantly related to perceptions of seven out of seventeen risks (smoking, HIV, GM food, transportation, natural disasters, terrorism, and stress). In all cases, feelings of social inclusion are correlated with lower risk perception. Even though social inclusion does not show such a straightforward result as previous experience, it is still an indication that feelings of not belonging to a larger community are related to higher risk perception. This is a telling point, since previous studies have not included vulnerability in the analysis of WME, following Flynn et al. ${ }^{(2)}$ Instead, earlier experiences have been used as independent variables of single risks. ${ }^{(7,49-52)}$

The relationship between risk perception and worldviews is more complex and less stable than that between risk perception and vulnerability. None of the four cultural biases (fatalism, egalitarianism, hierarchy, and individualism) correlate with perceptions of more than seven risks after controlling for gender, ethnicity, WME, age, education, marital status, and vulnerability. Interestingly, fatalists and individualists show similar patterns of giving high ratings to personal risks such as smoking, alcohol, and HIV, while egalitarians are more in line with what might be expected for they perceive some societal risks to be relatively greater than others, including climate change, GM food, transportation, and natural disasters, but technological systems and terrorism as lower. People with a hierarchical world-view perceive risks related to social order such as violence and terrorism as high, while personal risks such as HIV and alcohol as low. The conclusion is that Swedes do not differ much from other populations in terms of the relationship between different world-views, but that the link between worldviews and individual risk perception is not particularly stable.

Lastly, we find that the control variables of age, education, and marital status have stable but few correlations with risk perception. Old people have higher risk perception than 
young people with one notable exception: stress-related risks. Education does not play a particularly important role, for it is significantly related to perceptions of six different risks. In all cases but two - smoking and alcohol - people with more education show higher risk perception than people with less education. Similarly, marital status is only related to six instances of risk perception: being single means higher risk perception of smoking, HIV, violence, and epidemics but a lower risk perception of stress. The unexpected result, given previous studies, is that the biggest difference is the effect of education. Previous studies of the WME have typically shown that higher levels of education are related to lower risk perceptions, and not only among white males. ${ }^{(2)}$ The conclusion therefore is that the correlation between risk perception and education is weak and varying.

One further aspect of the WME remains. Previous studies have shown that it is not all white males that rate risk to be low, but rather a subset of well-educated, politically conservative men noted for their hierarchical and individualistic world-views. Considering the results from this study, the obvious conclusion would be that there is no such subset among Swedish native men since there is no clear WME in our material. However, since this study aims to compare Swedish data with previous American investigations, separate analyses were conducted on people with low risk perceptions. Given that white males do not stand out as a separate group, we chose to include all respondents who rate the seventeen risks as low, comparing them to those who rate them as medium or high, divided between the four groups investigated: native men, native women, men with foreign backgrounds, and women with foreign backgrounds; in all, eight groups. ${ }^{\text {vii }}$ One-way analysis of variance (ANOVA) was used to test if the low risk responders, and particularly the native men, differ from medium and high risk responders. ${ }^{\text {viii }}$ The variables included in the analyses were worldviews, experience of risk, social inclusion, age, and education.

The results show that there are significant differences between these groups for all variables, although not in the way expected. We will not describe these results in detail, for a few examples will suffice to show how different our results are compared to previous studies from the US. Beginning with education, so frequently referred to as related to the subset of low risk-rating white males in the US, our analysis shows that this group does not differ from white males with medium or high risk perceptions, or from people with foreign backgrounds. Native women with low risk ratings is the group with the highest education, followed by men with foreign backgrounds with low risk ratings, and native women rating risk to be non-low 
$(\mathrm{F}=2.656)$. White males in the US who perceive risk to be low have also been shown to have hierarchical and individualistic world-views. ${ }^{(1,2)}$ Our analyses show that native men who perceive risk to be low do not have more hierarchical worldviews that other groups, and as a matter of fact, native men who rate risk to be high are more hierarchical than this group, as are native women in general $(\mathrm{F}=2.718)$. However, people with foreign backgrounds, regardless of gender and high or low risk perception, have less hierarchical worldviews than native people. Native men with low risk perceptions are not the most individualistic either; on the contrary, this is true of men with foreign backgrounds with non-low risk perception $(\mathrm{F}=12.169)$. The group that differs most from the others is native women with low risk perception who are relatively speaking less individualistic. Lastly, there are great differences between native respondents and respondents with foreign backgrounds concerning social inclusion $(\mathrm{F}=28.324)$, but although native men with low risk perception see themselves as enjoying greater social inclusion, this difference is not significant. It is women, particularly women with low risk perception, who are most socially included. The fact that we used foreign background rather than different native population groups to define ethnicity might have an impact, and the results for social inclusion should be understood in relation to this fact.

Seen as a whole, the results show that previous experience and having a foreign background are the two variables that correlate with the greatest risk perception, while gender is the variable that correlates with the smallest risk perception. Explicitly testing the combination of being a man and a native - WME - did not result in any correlations at the 95 per cent level of significance. Furthermore, there is no subset of white males with comparably low risk perceptions and specific socio-economic characteristics. Hence, in Sweden ethnicity tends to influence risk perception, while gender does not. Explanatory factors such as worldviews and vulnerability play an important role, but the patterns are not similar to the patterns of previous American studies.

\section{DISCUSSION}

The results of the study reveal no general differences in risk perception in Sweden between men and women, only between native people and people with foreign backgrounds. This finding contradicts many previous studies, particularly those based on data from the $\mathrm{US},{ }^{(1,2,18,29)}$ but is consistent with the ambiguity gender has shown in previous Swedish 
studies of risk perception of general and environmental concerns in particular. ${ }^{(10,24,28)}$ Another finding that challenges previous research is that white males' risk perception does not stand out in comparison to those of other groups. The descriptive analyses seem to indicate the existence of WME, but the analytic multivariate analyses reveal that this effect is not stable when other factors are included in the analysis. The analytic analyses of worldviews and vulnerability, on the other hand, show that differences in risk perception between native people and people with foreign backgrounds persist even after these factors have been controlled for. Hence, there is no pure 'white male effect' in Sweden: it is just a 'white effect', since the white majority shows low risk perception, regardless of gender.

Furthermore, the findings support the assumption that structures at the societal level influence individual risk perception, and that differences between men and women and ethnic groups cannot be explained entirely using biological or psychological perspectives, for example. Compared to many other countries, Sweden is broadly gender equal, but has not come as far regarding racial equality. Consequently, our conclusion is that in terms of risk, Swedish women perceive the world no differently than Swedish men, because women have largely the same opportunities and life chances as men. People originating from Africa, South America and Asia, on the other hand, do not have the same living conditions in Sweden as native people have. On the contrary, they face greater unemployment, poverty, and segregation, which may well influence their view of risk and security in life. That said, it is important to emphasize that it is not 'ethnicity' per se that is the explanatory factor here, but rather what it mediates: inequality, discrimination, and a number of other factors related to an ethnically stratified population. To illustrate this, take our sample of people with foreign background: the sample can scarcely be categorized as a homogeneous group when it comes to ethnicity, considering that it consists of people from all over the world except Western Europe. Consequently, there must be something other than ethnicity that influences their perceptions, and our suggestion is inequality based on discrimination against foreigners. However, this inequality is channeled through ethnicity.

Finucane et al. ${ }^{(1)}$ point out that the individual characteristics of the person facing the risk are also important predictors for risk perception. Correspondingly, this study has also shown that the two individual vulnerability predictors - previous experience and social inclusion play an important independent role for risk perception; people exposed to risk and not feeling part of the surrounding society rate risks higher than others. Although not broken down by 
group, it is significant that inequality is related to risk perception at an individual level as well. At the same time, it is also interesting that the effect of ethnicity remains more or less the same after including individual inequality in the analyses. Thus we conclude that inequality, and possibly vulnerability, impacts on both a societal and an individual level in a way that might have a unique, parallel effect on individual risk perception. One interesting question here is whether it is possible to identify differences between cohorts of people with foreign backgrounds. As our data does not allow us to clarify these matters, they remain an important task for future research. However the contribution of this study to the study of risk perception is twofold: it reveals the influence of inequality at both a societal and individual level, and it shows that gender and ethnicity are not explanatory factors per se.

The impact of societal inequality on individual risk perception also calls our attention to other vulnerable population groups. For instance, do homo- and bisexual people have higher risk perception than heterosexuals, and do people with physical and mental disorders differ in their risk perception from people without such disorders? These groups are often marginalized, discriminated, and treated differently than the majority population, and if our hypothesis of a relationship between inequality at the societal level and risk perception at the individual level is correct, these groups will also show higher risk perception. Additional research is called for to investigate this hypothesis, which would be better called the 'societal inequality effect' than the 'white male effect'.

Lastly, it should be noted that the study has its limitations, of which four in particular should be borne in mind when interpreting the results. The first concerns the definition of the WME, which in the original studies from the US was based on different ethnical population groups rather than immigration as in the present case. We argue that native Swedes are comparable to the 'white' ethnic group in the US, but only further research will establish whether this assumption is correct. The other issues are related to the data and its limitations. The low number of respondents with foreign backgrounds is one such limitation, reducing the representativeness of the study and possibly also reducing the ability to observe effects. Furthermore, due to the difficulties Swedish surveys experience in contacting people with foreign backgrounds, the sample is most probably biased: we cannot say in which ways, but considering the low response rate and the fact that the questionnaire was in Swedish, we suspect that the respondents answering the survey are positively biased in terms of education and language skills. What might justify using a biased sample like this is the fact that the nature of the bias ought to make the difference between native people and people with foreign 
backgrounds smaller rather than larger, given the latter sample is fluent in Swedish. It is to be hoped that future experimental studies can solve this problem. Lastly, it would have been desirable to investigate possible differences between first- and second-generation immigrants, particularly since social inclusion might be expected to vary between these groups, yet due to sample limitations such an analysis was not possible, and remains an issue for future research.

Although our conclusions should be understood in the light of these limitations, the study's findings are new, reasonably robust and challenge previous research about differences in risk perception between men and women.

\section{ACKNOWLEDGMENTS}

This work was supported by The Swedish Research Council, which is gratefully acknowledged. The authors wish to thank the colleagues in the ROHS II project, Susanna Öhman, Jörgen Sparf and Erika Wall, for their helpful comments on an earlier draft of this manuscript. The authors also wish to thank the anonymous reviewers who offered detailed comments and wise suggestions. 


\section{REFERENCES}

1. Finucane ML, Slovic P, Mertz CK, Flynn J, Satterfield TA. Gender, race, and perceived risk: the 'white male' effect. Health, Risk \& Society. 2000 2(2):159-172.

2. Flynn J, Slovic P \& Mertz CK. Gender, race, and perception of environmental health risks. Risk Analysis. 1994 14(6):1101-1109.

3. Kahan DM, Braman D, Gastil J, Slovic P, Mertz CK. Culture and Identity-Protective Cognition: Explaining the White Male Effect in Risk Perception. Journal of Empirical Legal Studies. 2007 4(3):465-505.

4. Kalof L, Dietz T, Gaugnano G, Stern PC. Race, gender and environmentalism: the atypical values and beliefs of white men. Race, Gender and Class. 2002 9(2):1-19.

5. Palmer CGS. Risk perception: another look at the 'white male' effect. Health, Risk \& Society. 2003 5(1):71-83.

6. Kahan DM, Slovic P, Braman D, Gastil J, Cohen G. Nanotechnology risk perception: The influence of affect and values. Culture Cognition Project Working Paper No. 22. Available at: http://research.yale.edu/culturecognition. Accessed on August 11, 2008.

7. Satterfield TA, Mertz CK, Slovic P. Discrimination, vulnerability, and justice in the face of risk. Society for Risk Analysis. 2004 24(1):115-129.

8. Franzen A. Environmental attitudes in international comparison: An analysis of the ISSP surveys 1993 and 2000. Social Science Quarterly. 2003 84(2):297-308.

9. Hayes BC. Gender, scientific knowledge, and attitudes toward the environment: A crossnational analysis. Political Research Quarterly. 2001 54(3):657-671.

10. Olofsson A, Öhman S. General beliefs and environmental concern. Transatlantic Comparisons. Environment and Behavior. 2006 38(6):768-790.

11. Pakulski J, Tranter B, Crook S. The dynamics of environmental issues in Australia: Concerns, clusters and carriers. Australian Journal of Political Science. 1998 33(2):235252.

12. Dunlap RE, Michelson W (eds). Handbook of environmental sociology. Westport: Greenwood, 2002.

13. Esping-Andersen G. The Three Worlds of Welfare Capitalism. Cambridge: Polity Press, 1990.

14. Svallfors S (ed). The Political Sociology of the Welfare State: Institutions, Social Cleavages and Orientations. Stanford: Stanford University Press, 2007.

15. Johnson BB. Gender and race in beliefs about outdoor air pollution. Risk Analysis. 2002 22(4):725-738.

16. Brody CJ. Differences by sex in support for nuclear power. Social Forces. 1984 63(1):209-228.

17. Davidson DJ, Freudenberg WR. Gender and environmental risk concerns: A review and analysis of available research. Environment \& Behavior. 1996 28(3):302-339.

18. Gutteling J, Wiegman O. Gender specific reactions to environmental hazards in the Netherlands. Sex Roles. 1993 28(7/8):433-447.

19. Johnson BB. Arguments for testing ethnic identity and acculturation as factors in risk judgments. Risk Analysis. 2004 24(5):1279-1287.

20. Johnson CY, Bowker JM, Cordell KH. Ethnic variation in environmental belief and behavior: An examination of the new ecological paradigm in a social psychological context. Environment and Behavior. 2004 36(2):157-186.

21. Mohai P. Men, women, and the environment: An examination of the gender gap in environmental concern and activism. Society and Natural Resources. 1992 5(1):1-19.

22. Mohai P, Bryant B. Is there a 'race' effect on concern to environmental quality? Public Opinion Quarterly. 1998 62(4):475-505. 
23. Öhman S. Public perceptions of gene technology: On the edge of risk society? Umeå: Umeå University, 2002.

24. Öhman S. Different shades of green: Lifestyles and environmental attitudes in Sweden. Miller, JD (ed). Perceptions of biotechnology: Public understanding and attitudes. Cresskill, NJ: Hampton Press, 2001.

25. Whittaker M, Segura GM, Bowler S. Racial/ethnic group attitudes toward environmental protection in California: Is 'environmentalism' still a white phenomenon? Political Research Quarterly. 2005 58(3):435-447.

26. Zinn HC, Pierce CL. Values, gender, and concern about potentially dangerous wildlife. Environment and Behavior. 2002 34(2):239-256.

27. Enander, A. Människors förhållningssätt till risker, olyckor och kriser. Karlstad: Räddningsverket, 2005.

28. Enander A, Johansson A. Säkerhet och risker i vardagen: en studie av uppfattningar, värderingar och beteenden hos allmänheten i Sverige. Karlstad: Räddningsverket, 2002.

29. Gustafsson PE. Gender differences in risk perception: Theoretical and methodological perspectives. Risk Analysis. 1998 18(6):805-811.

30. Olofsson A. Crisis communication in multicultural societies: A study of municipalities in Sweden. International Journal of Mass Emergencies and Disasters. 2007 25(2):145-172.

31. Olofsson A, Öhman S. Views of risk in Sweden: Global fatalism and local control. An empirical investigation of Ulrich Beck's theory of modern risks. Journal of Risk Research. 2007 10(2):177-196.

32. Hakes JK, Viscusi WK. Dead Reckoning: Demographic Determinants of the accuracy of Mortality Risk perception. Risk Analysis. 2004 24(3):651-664.

33. Barke RP, Jenkins-Smith, Slovic P. Risk perception of men and women scientists. Social Science Quarterly. 1997 78(1):167-176.

34. Slovic P. Are trivial risks the greatest risks of all? Journal of Risk Research. 1999 2(4):281-288.

35. Slovic P. The perception of risk. London: Earthscan Publications, 2000.

36. Douglas M. Natural symbols: Explorations in cosmology. London: Barrie \& Rockliff, 1970.

37. Douglas M, Wildavsky A. Risk and culture. An essay on the selection of technological and environmental dangers. Berkeley, CA: University of California Press, 1982.

38. Dake K. Orienting dispositions in the perception of risk. An analysis of contemporary worldviews and cultural biases. Journal of Cross-Cultural Psychology. 1991 22:61-82.

39. Wildavsky A, Dake K. Theories of risk perception: who fears what and why? Daedalus. 1990 119(4):41-60.

40. Grendstad G, Selle P. Cultural theory, postmaterialism and environmental attitudes. In Ellis RJ, Thompson M (eds). Culture matters: Essays in honor of Aaron Wildavsky. Boulder, CO: Westview, 1997.

41. Marris C, Langford IH, O'Riordan T. A quantitative test of the cultural theory of risk perception: Comparison with the psychometric paradigm. Risk Analysis. 1998 18(5):635-647.

42. Peters E, Slovic P. The role of affect and worldviews as orienting dispositions in the perception and acceptance of nuclear power. Journal of Applied Social Psychology. 1996 26(16):1427-1453.

43. Rippl S. Cultural theory and risk perception: a proposal for a better measurement. Journal of Risk Research. 2002 5(2):147-165.

44. Slimak MW, Dietz T. Personal values, beliefs, and ecological risk perception. Risk Analysis. 2006 26(6):1689-1705. 
45. Stern PC. New Environmental Theories: Toward a Coherent Theory of Environmentally Significant Behavior. Journal of Social Issues. 2000 56(3):407-424.

46. Stern PC, Dietz T, Abel T, Guagnano GA, Kalof L. A value-belief-norm theory of support for social movements: The case of environmental concern. Human Ecology Review. 1999 6(8):1-97.

47. Savage I. Demographic Influences on Risk perception. Risk Analysis. 1993 13(4):413420.

48. Marshall, BK. Gender, race and perceived environmental risk: The 'white male' effect in Cancer Valley, LA. Sociological Spectrum. 2004 24(4):453-478.

49. Barnshaw J, Trainor J. Race, class and capital amidst the hurricane Katrina Diaspora. In Brunsma DL, Overfelt D, Picou JS (eds). The sociology of Katrina: Perspectives on a Modern Catastrophe. Boulder, CO: Rowman \& Littlefield, 2007.

50. Morrow HB. Identifying and mapping community vulnerability. Disasters. 1999 23(1):118.

51. Wisner BP, Blaikie T, Cannon, I, Davis I. At Risk: Natural Hazards, People's Vulnerability and Disasters. London: Routledge, 2004.

52. Fothergill A, Maester G M, Darlington JD. Race, ethnicity and disasters in the United States: A review of the literature. Disasters. 1999 23(2):156-173.

53. Inglehart R, Welzel C. Modernization, Cultural Change and Democracy: The Human Development Sequence. Cambridge: Cambridge University Press, 2005.

54. Rokeach M. The nature of human values. New York: Free Press, 1973.

55. Schwartz SH, Blisky W. Toward a psychological structure of human values. Journal of Personal Social Psychology. 1987 53(3) 550-562.

56. United Nations Development Program. Available at: http://www.undp.org, Accessed on December 1, 2008.

57. Lopez-Carlos A, Zahidi S. Women's empowerment: Measuring the global gender gap. Geneva: World Economic Forum. Available at: http://www.weforum.org. Accessed on June 2, 2008.

58. Portes A, Rumbaut R. Legacies: The Story of the Immigrant Second Generation. Berkeley, CA: University of California Press, 2001.

59. Statistics Sweden. Available at: http://www.scb.se, Accessed on January 15, 2009.

60. Arai M, Regnér H, Schröder L. Är arbetsmarknaden öppen för alla? Appendix 6 of Långtidsutredningen 1999 (SOU 2000:7). Fritzes: Stockholm, 1999.

61. Rashid S. Internal migration and income of immigrant families. Journal of Immigrants and Refugee Studies. 2009 7(2):180-200.

62. de los Reyes P, Kamali M (eds). Bortom Vi och Dom. Teoretiska reflektioner bortom makt, integration och strukturell diskriminering (SOU 2005:41). Stockholm: Fritzes, 2005.

63. Carlsson M, Rooth D. Etnisk diskriminering på svensk arbetsmarknad - resultat från ett fältexperiment. Ekonomisk Debatt. 2007 35(3):55-68.

64. Schmauch U. Den osynliga vardagsrasismen. Umeå: Umeå universitet, 2006.

65. Coussey M. Tackling racial equality: International comparisons. Home Office Research Study 238. Available at: http://www.homeoffice.gov.uk, Accessed on February 3, 2009.

66. Sjöberg L. Factors in risk perception. Risk Analysis. 2000 20(1):1-11.

67. McEachrane M, Faye L. Sverige och de Andra: Postkoloniala perspektiv. Stockholm: Natur och Kutur, 2001.

68. Svanberg I, Tydén M. I nationalismens bakvatten. Lund: Studentlitteratur, 1999.

69. Greene, WH. Econometric Analysis. $2^{\text {nd }}$ edn. New York: MacMillan, 1993. 
70. Inglehart R, Norris P. Rising tide - Gender equality and cultural change around the world. Cambridge: Cambridge University Press, 2003.

71. United Nations Development Program. Human Development Report 2009. Overcoming barriers: Human mobility and development. New York: Palgrave Macmillan. Available at: http://hdr.undp.org, Accessed on January 20, 2010.

72. Olsen GM. Labour Market Policy in the United States, Canada and Sweden: Addressing the Issue of Convergence. Social Policy \& Administration. 2008 42(4):323-341.

73. Olofsson A, Öhman S. Risk perception and risk behaviour in a heterogeneous society: The case of Sweden. In Zinn J (ed). Differences, Inequalities and the Generational Reproduction of Risk. Farnham: Aschgate, forthcoming.

74. Fischer GW, Morgan MG, Fischhoff B, Nair I, Lave LB. What Risks Are People Concerned About. Risk Analysis. 1991 11(2):303-314.

75. Lacatus C. What is a blatte? Migration and ethnic identity in contemporary Sweden. Journal of Arab and Muslim Media Research. 2007 1(1):79-92.

76. Rivers L, Joseph A, Slovic P. Beyond a simple case of black and white: Searching for the White Male Effect in the African-American community. Risk Analysis. 2010 30(1):6577. 
How to cite: Olofsson, A. and Rashid, S. (2011), The White (Male) Effect and Risk Perception: Can Equality Make a Difference? Risk Analysis, 31: 1016-1032. doi: 10.1111/j.1539-6924.2010.01566.x

Table A. Regression analysis (ordered probit model), Model 1, of the relationship between risk perception and gender, ethnicity, age, education, and marital status.

\begin{tabular}{|c|c|c|c|c|c|c|c|c|c|}
\hline Explanatory Variables & GEN & $E T H$ & WME & $\overline{A G E}$ & $E D U 1$ & EDU2 & SING & $P s R^{2}$ & $N-O B S$ \\
\hline \multicolumn{10}{|l|}{ Dependent Variables } \\
\hline Smoking & -0.08 & $0.67^{\star \star \star}$ & -0.06 & $0.01^{* \star *}$ & -0.09 & $-0.37^{\star \star \star}$ & $0.30^{* \star *}$ & 0.03 & 1190 \\
\hline Alcohol & 0.20 & $0.27^{\star}$ & -0.05 & 0.001 & -0.06 & $-0.20^{\star *}$ & 0.10 & 0.01 & 1201 \\
\hline HIV & 0.13 & $0.77^{\star \star *}$ & -0.03 & -0.004 & -0.05 & -0.12 & $0.34^{\star \star *}$ & 0.04 & 1190 \\
\hline Climate change & $-0.30^{*}$ & 0.10 & 0.02 & -0.001 & -0.06 & -0.02 & 0.72 & 0.01 & 1183 \\
\hline Fire & -0.16 & $0.46^{* *}$ & 0.06 & 0.002 & 0.02 & -0.04 & 0.05 & 0.01 & 1196 \\
\hline GMO & -0.24 & $0.40^{* * *}$ & -0.03 & 0.003 & 0.13 & 0.12 & 0.07 & 0.01 & 1198 \\
\hline Transportation & -0.13 & $0.51^{\star \star *}$ & 0.12 & $0.01^{* \star \star}$ & 0.01 & 0.02 & 0.11 & 0.02 & 1194 \\
\hline Natural disasters & $-0.42^{* *}$ & $0.86^{* * *}$ & 0.13 & $0.006^{* \star *}$ & -0.05 & -0.10 & 0.12 & 0.03 & 1199 \\
\hline Violence & -0.17 & $0.51^{* * *}$ & 0.31 & 0.001 & 0.01 & 0.05 & $0.21^{\star * *}$ & 0.01 & 1189 \\
\hline BSE & -0.29 & $0.99^{* * *}$ & 0.10 & $0.01^{* *}$ & 0.10 & -0.10 & 0.09 & 0.04 & 1181 \\
\hline Technological systems & 0.02 & -0.03 & -0.06 & 0.002 & $0.22^{* *}$ & $0.34^{* * *}$ & -0.03 & 0.01 & 1184 \\
\hline Accidents (leisure time) & $-0.34^{*}$ & 0.23 & $0.40^{* *}$ & -0.003 & $0.22^{* *}$ & 0.10 & $0.13^{*}$ & 0.01 & 1190 \\
\hline Terrorism & -0.19 & $0.79^{* * *}$ & -0.02 & $0.01^{* \star \star}$ & -0.03 & -0.07 & $0.16^{* *}$ & 0.03 & 1185 \\
\hline Stress & $-0.38^{* *}$ & $0.47^{\star \star *}$ & 0.18 & $-0.01^{\star \star \star}$ & 0.12 & $0.19^{* *}$ & $-0.16^{\star \star}$ & 0.03 & 1194 \\
\hline Epidemics & -0.17 & $0.67^{* \star *}$ & -0.02 & $0.01^{* \star \star}$ & -0.13 & -0.13 & $0.17^{\star \star}$ & 0.03 & 1184 \\
\hline Cancer & -0.07 & 0.21 & -0.18 & $0.01^{\star \star \star}$ & 0.06 & 0.04 & 0.07 & 0.02 & 1204 \\
\hline Traffic accidents & -0.05 & $0.31^{* *}$ & 0.04 & 0.003 & -0.01 & -0.05 & 0.01 & 0.01 & 1201 \\
\hline
\end{tabular}


How to cite: Olofsson, A. and Rashid, S. (2011), The White (Male) Effect and Risk Perception: Can Equality Make a Difference? Risk Analysis, 31: 1016-1032. doi: 10.1111/j.1539-6924.2010.01566.x

Table B. Regression analysis (ordered probit model), Model 2, of the relationship between risk perception and gender, ethnicity, age, education, marital status, and worldviews.

\begin{tabular}{|c|c|c|c|c|c|c|c|c|c|c|c|c|c|}
\hline Explanatory Variables & GEN & $E T H$ & WME & $\overline{A G E}$ & $E D U 1$ & EDU2 & SING & FAT & $E G A$ & HIE & IND & $P s R^{2}$ & $N$-OBS \\
\hline \multicolumn{14}{|l|}{ Dependent Variables } \\
\hline Smoking & -0.08 & $0.49^{* \star *}$ & -0.12 & $0.01^{\star \star \star}$ & -0.02 & $-0.28^{* \star *}$ & $0.28^{* * *}$ & $0.10^{* * *}$ & $0.09^{* * *}$ & -0.05 & $0.14^{\star \star \star}$ & 0.04 & 1190 \\
\hline Alcohol & 0.18 & 0.16 & -0.09 & 0.003 & -0.03 & $-0.18^{*}$ & 0.08 & 0.06 & 0.002 & $-0.08^{* *}$ & $0.12^{\star * \star}$ & 0.01 & 1201 \\
\hline HIV & 0.08 & $0.64^{\star \star \star}$ & -0.08 & -0.001 & -0.02 & -0.10 & $0.32^{\star \star \star}$ & 0.06 & -0.02 & $-0.09^{* *}$ & $0.16^{\star \star \star}$ & 0.05 & 1190 \\
\hline Climate change & $-0.29^{*}$ & 0.07 & 0.02 & -0.001 & -0.05 & 0.01 & 0.06 & -0.02 & $0.09^{* * *}$ & -0.02 & 0.04 & 0.01 & 1183 \\
\hline Fire & -0.18 & $0.40^{\star * *}$ & 0.04 & 0.003 & 0.04 & -0.03 & 0.04 & 0.02 & -0.01 & -0.03 & $0.07^{* *}$ & 0.01 & 1196 \\
\hline GMO & -0.22 & $0.39^{* * *}$ & -0.01 & 0.003 & 0.15 & $0.18^{\star}$ & 0.07 & -0.01 & $0.08^{* * *}$ & 0.03 & -0.02 & 0.02 & 1198 \\
\hline Transportation & -0.11 & $0.45^{* * *}$ & 0.10 & $0.01^{* \star *}$ & 0.04 & 0.08 & 0.10 & 0.04 & $0.08^{* * *}$ & -0.01 & 0.007 & 0.02 & 1194 \\
\hline Natural disasters & $-0.41^{* *}$ & $0.80^{* * *}$ & 0.12 & $0.006^{* \star *}$ & -0.02 & -0.05 & 0.11 & 0.03 & $0.07^{\star *}$ & -0.001 & 0.05 & 0.04 & 1199 \\
\hline Violence & -0.19 & $0.54^{* \star *}$ & 0.32 & 0.001 & 0.03 & 0.07 & $0.22^{\star \star *}$ & -0.01 & -0.05 & $0.09^{* * *}$ & 0.05 & 0.01 & 1189 \\
\hline$B S E$ & -0.29 & $0.87^{* * *}$ & 0.06 & $0.01^{* \star *}$ & 0.17 & 0.03 & 0.07 & $0.12^{* \star *}$ & 0.01 & 0.05 & $0.10^{\star * *}$ & 0.05 & 1181 \\
\hline Technological systems & -0.01 & -0.03 & -0.07 & 0.003 & $0.21^{\star *}$ & $0.31^{* \star *}$ & -0.03 & -0.01 & $-0.06^{* *}$ & -0.01 & 0.05 & 0.01 & 1184 \\
\hline Accidents (leisure time) & $-0.36^{*}$ & $0.29^{*}$ & $0.40^{* *}$ & -0.003 & $0.20^{* *}$ & 0.04 & $0.13^{*}$ & -0.05 & -0.05 & -0.01 & 0.002 & 0.01 & 1190 \\
\hline Terrorism & -0.21 & $0.75^{\star \star *}$ & -0.04 & $0.10^{* * *}$ & 0.003 & -0.02 & $0.15^{\star \star}$ & 0.05 & $-0.05^{*}$ & 0.05 & $0.07^{* *}$ & 0.04 & 1185 \\
\hline Stress & $-0.39^{* *}$ & $0.43^{* * *}$ & 0.17 & $-0.01^{* * \star}$ & 0.15 & $0.26^{* * *}$ & $-0.17^{* *}$ & 0.01 & 0.04 & $0.06^{*}$ & $0.09^{* *}$ & 0.03 & 1194 \\
\hline Epidemics & -0.18 & $0.63^{* * *}$ & -0.03 & $0.01^{* * *}$ & -0.11 & -0.10 & $0.16^{\star *}$ & 0.02 & -0.01 & 0.01 & 0.05 & 0.03 & 1184 \\
\hline Traffic accidents & -0.07 & $0.31^{*}$ & 0.03 & 0.003 & -0.01 & -0.06 & 0.01 & -0.003 & -0.04 & 0.001 & 0.03 & 0.01 & 1201 \\
\hline
\end{tabular}


How to cite: Olofsson, A. and Rashid, S. (2011), The White (Male) Effect and Risk Perception: Can Equality Make a Difference? Risk Analysis, 31: 1016-1032. doi: 10.1111/j.1539-6924.2010.01566.x

Table C. Regression analysis (ordered probit model), Model 3, of the relationship between risk perception and gender, ethnicity, age, education, marital status, earlier experiences of risk, social inclusion, and worldviews.

\begin{tabular}{|c|c|c|c|c|c|c|c|c|c|c|c|c|c|c|c|}
\hline Explanatory Variables & GEN & ETH & WME & $\overline{A G E}$ & EDU1 & EDU2 & SING & $\overline{F A T}$ & $E G A$ & HIE & IND & $E X P$ & S.INCL & $P s R^{2}$ & $\begin{array}{l}N- \\
O B S\end{array}$ \\
\hline \multicolumn{16}{|l|}{ Dependent Variables } \\
\hline Smoking & -0.04 & $0.37^{* \star *}$ & -0.19 & $0.01^{* \star \star}$ & -0.04 & $-0.29^{* *}$ & $0.25^{* * *}$ & $0.10^{* * *}$ & $0.09^{\star *}$ & -0.02 & $0.13^{* * *}$ & $0.14^{* * *}$ & $-0.09^{* *}$ & 0.05 & 1187 \\
\hline Alcohol & 0.22 & 0.13 & -0.15 & 0.003 & -0.06 & $-0.18^{*}$ & 0.06 & $0.06^{*}$ & 0.002 & $-0.08^{* *}$ & $0.11^{* * *}$ & $0.14^{* \star *}$ & 0.01 & 0.02 & 1198 \\
\hline HIV & 0.12 & $0.59^{* * *}$ & -0.13 & -0.001 & -0.04 & -0.10 & $0.31^{\star \star \star}$ & $0.07^{*}$ & -0.02 & $-0.08^{* *}$ & $0.15^{* \star *}$ & $0.10^{\star *}$ & -0.03 & 0.06 & 1187 \\
\hline Climate change & -0.27 & -0.04 & -0.03 & -0.001 & -0.05 & 0.01 & 0.04 & -0.02 & $0.09^{\star \star \star}$ & 0.001 & 0.02 & $0.08^{\star \star}$ & $-0.09^{* *}$ & 0.01 & 1180 \\
\hline Fire & -0.12 & $0.38^{* *}$ & -0.04 & 0.003 & 0.02 & -0.01 & 0.02 & 0.03 & -0.004 & -0.03 & $0.07^{* *}$ & $0.15^{* * *}$ & 0.02 & 0.02 & 1192 \\
\hline GMO & -0.19 & $0.31^{* *}$ & -0.07 & 0.003 & 0.13 & $0.18^{*}$ & 0.05 & 0.01 & $0.09^{* \star *}$ & 0.05 & -0.03 & $0.16^{\star \star *}$ & -0.03 & 0.02 & 1195 \\
\hline Transportation & -0.06 & $0.35^{\star *}$ & 0.03 & $0.01^{\star \star \star}$ & 0.01 & 0.07 & 0.07 & -0.04 & $0.08^{* \star *}$ & 0.01 & -0.004 & $0.16^{* \star *}$ & $-0.06^{*}$ & 0.03 & 1191 \\
\hline Natural disasters & $-0.36^{* *}$ & $0.66^{* * *}$ & 0.03 & $0.006^{\star \star *}$ & -0.04 & -0.05 & 0.07 & 0.03 & $0.06^{* *}$ & 0.03 & 0.03 & $0.16^{* * *}$ & $-0.11^{* * *}$ & 0.05 & 1196 \\
\hline Violence & -0.12 & $0.41^{\star \star}$ & 0.21 & 0.00 & 0.001 & 0.06 & $0.18^{* *}$ & -0.01 & -0.05 & $0.13^{* * *}$ & 0.03 & $0.19^{* * *}$ & $-0.10^{* *}$ & 0.02 & 1186 \\
\hline$B S E$ & -0.24 & $0.80^{* * *}$ & -0.01 & $0.01^{\star \star \star}$ & 0.15 & 0.03 & 0.05 & $0.13^{* \star *}$ & 0.01 & $0.07^{*}$ & $0.09^{* * *}$ & $0.12^{* * *}$ & -0.04 & 0.06 & 1178 \\
\hline Technological systems & 0.03 & -0.07 & -0.12 & 0.003 & $0.20^{* *}$ & $0.30^{\star \star \star}$ & -0.04 & -0.01 & $-0.06^{\star *}$ & -0.002 & 0.05 & 0.06 & -0.03 & 0.01 & 1181 \\
\hline Accidents (leisure time) & -0.31 & $0.28^{*}$ & $0.35^{*}$ & -0.003 & $0.17^{*}$ & 0.04 & $0.13^{*}$ & -0.05 & -0.05 & -0.01 & -0.01 & $0.15^{\star * *}$ & 0.03 & 0.01 & 1188 \\
\hline Terrorism & -0.17 & $0.66^{* * *}$ & -0.12 & $0.01^{* * *}$ & -0.03 & -0.03 & 0.12 & 0.04 & $-0.06^{*}$ & $0.08^{* *}$ & $0.06^{*}$ & $0.18^{* * *}$ & $-0.07^{*}$ & 0.05 & 1183 \\
\hline Stress & $-0.35^{* *}$ & $0.31^{* *}$ & 0.10 & $-0.01^{* \star \star}$ & 0.12 & $0.24^{* *}$ & $-0.21^{* * *}$ & 0.01 & 0.04 & $0.09^{* * *}$ & $0.07^{* *}$ & $0.17^{* * *}$ & $-0.09^{* *}$ & 0.04 & 1191 \\
\hline Epidemics & -0.14 & $0.55^{* * *}$ & -0.10 & $0.01^{* * *}$ & -0.13 & -0.11 & $0.14^{*}$ & 0.03 & -0.01 & 0.03 & 0.04 & $0.14^{\star * *}$ & -0.05 & 0.04 & 1181 \\
\hline Cancer & -0.01 & 0.08 & -0.30 & $0.01^{\star \star \star}$ & 0.04 & 0.06 & 0.03 & 0.02 & -0.004 & 0.02 & 0.05 & $0.22^{\star \star \star}$ & -0.04 & 0.03 & 1200 \\
\hline Traffic accidents & -0.01 & 0.26 & -0.04 & 0.003 & -0.03 & -0.06 & -0.001 & -0.001 & -0.04 & 0.01 & 0.02 & $0.09^{* *}$ & -0.03 & 0.01 & 1197 \\
\hline
\end{tabular}




\footnotetext{
${ }^{\mathrm{i}}$ Foreign background was chosen rather than ethnicity since ethnicity is not used in Sweden to categorize people in public records.

ii The environmental injustice thesis is primarily related to studies of environmental risks.

iii The extremely low response rate in sample 2 is partly due to language problems and incorrect addresses. The first is a conjecture on our part, while we have empirical evidence of the latter. As many as 28 per cent of the respondents in sample 2 had no or an incorrect phone number listed, while the figure for the national sample is 9 per cent. This is an indication that all respondents in sample 2 did not even receive the questionnaire.

iviv The number of people originating from Western Europe and North America was so few they were excluded $(\mathrm{n}=22)$.

${ }^{\mathrm{v}}$ In order to test internal consistency, four separate Cronbach's Alpha were run for native men (NM), native women (NW), men with foreign backgrounds (FM), and women with foreign backgrounds (FW), against the seventeen risk perception variables, indicating satisfactory internal consistency for all four groups: NM .851, NW .841, FM .937, and FW .946.

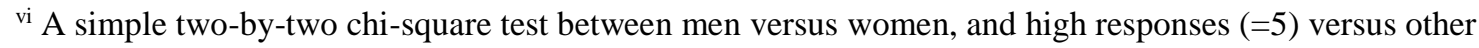
responses $(=1-4)$ was conducted for each risk. The authors can provide descriptions of the statistical analyses. vii To investigate people with low risk perceptions, an index of all seventeen risks was generated (Cronbach's Alpha $=.886$ ) and all respondents were assigned to either the low risk-rating group or the medium or high riskrating group according to their mean score. Mean scores lower than 2 were assigned to the low risk-rating group. These groups were then divided between men and women with native or non-native origin.

viii The statistical analyses are not described in detail but are available from the authors_All the ANOVA tests were done separately, with post hoc tests indicating the groups of respondents between which there were significant differences in the .95 per cent level. For the results described in the text, F-values are given (degrees of freedom=7).
} 